magnetic measure, on account of the supreme importance of such a measurement in the theory of light.

I may in conclusion refer to a possible objection. The force of "stiction" may be supposed to interfere with the reading of the limiting position of equilibrium. Practically the objection is groundless, for we ean always (force of stiction notwithstanding) attain this position very nearly. Having done so, a very slight tap on the base of the instrument is sufficient to free the disk and take it slightly out of focus, where it remains. Then move the plates forward by menns of the micrometer screw until the guard plate again catches up the disk. We thus get the position of equilibrium without the interference of stiction at all.

I am now having the instrument altered by Mr. Groves. A very light and flat gilt disk of mica suspended by silvered silk fibres will replace the aluminium disk, and the distance between the plates will be varied within very narrow limits, so as to show whether the cushion of air between the plates exercises any influence on the results.

The range of tilting of the plates will also be increased so as to allow of the employment of a large number of cells. In this case the equations previously used must be replaced by equations of the forms-

$$
\begin{aligned}
\operatorname{Sin}(\theta+\alpha) & =k \mathrm{E}^{2}, \\
\operatorname{Sin} \alpha & =k^{\prime} \mathrm{E}^{2}, \\
\tan (\theta+\alpha)-\tan \alpha & =c,
\end{aligned}
$$

where $k, k$, and $c$ are known constants. In these equations we can, of course, take $\alpha$ very small, as before, and get a very approximate and easily obtained solution by using expansions to the third order of small quantities-as I shall show in a subsequent communication on the completion of my experimeuts.

GEORGE M. MINCHIN

Royal Indian Engineering College, Cooper's Hill, December I

\section{VELOCITIES IN TIDAL RIVERS}

$A$ PAPER "On the Relative Value of Tidal and Upland Waters in maintaining Rivers, \&c.," by Mr. Walter R. Browne, M.Inst:C.E., late Fellow of Trinity College, Cambridge, has been lately published by the Institution of Civil Engineers. The main object of it is to prove, as a general prixciple, though by no means applicable in every case, that the main agent which keeps clear the channels of tidal rivers is not the run of tide passing up and down them every twelve hours, but the upland or fresh waters which pass down them at the period of low water, more or less aided by the oozing out of salt water which has soaked into the banks while covered with the tide.

The author, with a view to check his conclusions by actual experiment, resolved to investigate the actual velocity at the bottom of a tidal chamnel during an ebb tide; since it is clear that, whatever the velocity at the top, it is the bottom velocity alone which produces any scouring effect. In the very largest rivers, above the action of the tide, the bottom velocity differs but little from the surface velocity; but in smalter streams it is generally much less than the surface velocity, and the ratio between the two decreases rapidly as the depth increases. The case of a tidal river however is somewhat different, because then the level of the bottom is below the surface of the ocean outside, and this must have a certain effect in ponding back the river current. Accordingly two sets of experiments, made at a carefully-chosen spot on the River Avon at Bristol, showed that for about twothirds of an ebb tide, and even when the surface velocity was at its highest, the bottom velocity was absolutely nil. The water at the bottom then seemed to start suddenly into activity, and almost immediately assumed a velocity agreeing fairly with that observed in ordinary rivers above the tidal area. The two sets of experiments were made with different meters, at different states of the tides, and at different times of year; so that they amply confirmed each other. The stillness of the bottom was further proved by the board, supporting the rod on which the meter was hung, coming up with a deposit of silt upon its surface, showing that, far from any scouring being in progress, actual deposition was taking place. The second set of experiments was the most accurate, the meter having been specially made and tested for the purpose: The results are plotted on the accompanying diagram.

In the diagram the line $\mathrm{A} B$ represents the probable variation in the surface velocities as sketched from the various observa. tions. The small circles represent the observations made at different times by the meter, and the crosses represent observations made, as a check upon these, by floats at the surface. It will be seen that the meter observations are by far the most satisfactory. The line C D is similarly sketched from the observations of the velocities at the middle of the depth. It will be observed that here the maximum velocity is attained later than at the sur. face, and just when the latter is beginning to fall off. The line E F G and the circles contiguous to it refer to the bottom velocity. It will be seen that it rises from nothing to a tolerably high value, with very great abruptness, just at the time when the surface velocity begins to diminish : it is probable, however, that

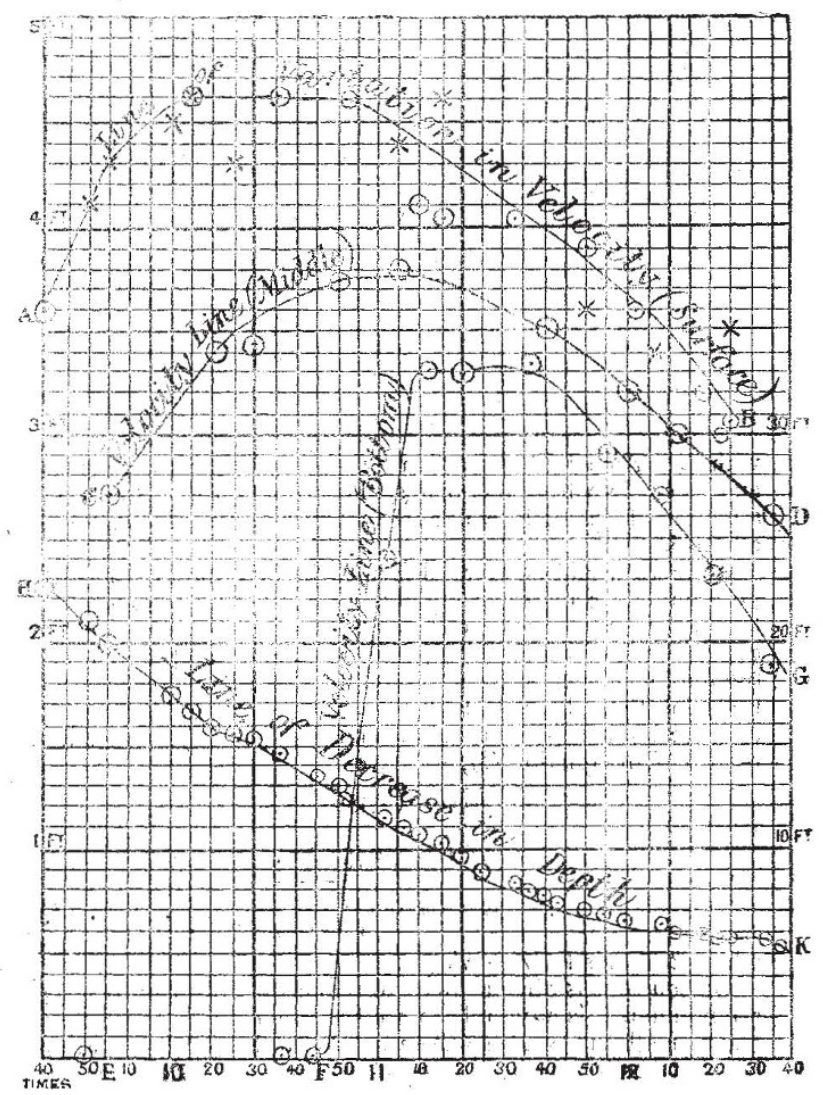

the change is not so much connected with this as with the decrease in depth, which is given by the line $\mathrm{H} \mathrm{K}$ and the contiguous circles. These are plotted to one-tenth the scale of the velocity observations, and the sudden flattening of the curves about 12 noon marks the beginning of what the author terms the low water perind.

It is believed that the fact of a current having a high velocity at the surface and absolutely none at the bottom has not been previously observed, and it may have considerable bearing on the general theory of the motion of rivers, as well as on the more practical points dealt with in the paper.

\section{ON THE ECONOMICAL USE OF GAS-ENGINES} FOR THE PRODUCTION OF ELECTRICITY $Y^{1}$

THE lecturer pointed out, that as long as the chief practical use of electricity was in telegraphy it was the quickness of action, rather than the ability to transmit large amounts of power to a distance, that formed the chief feature in the employment of electricity; but that in this exhibition the numerous practical examples of the electric transmission of power, rather than the electric transmission of signals, formed without doubt the leading feature.

Much had been heard about the dynamo-electric machines which generate the electric current; but while electricians were

I Abstract of a lecture delivered in French in the Salle du Congrès, at the Electrical Exhibition, Paris, by Prof. W. E. Ayrton, F.R S. 
engaged in considering the differences between the various kind; of the se machiiles and the improvements that can be effected in them, the mechanical engineer should give his carcful attention to the possible improvements that can be made in the engines that drive the electric generators.

As ling as the lighting of our large cities was performed by gas the cheap manufacture of illuminating gas was the important question, but now that electric lighting bids fair to displace other systems the question that has special interest is, not the extraction of illuminating gas from conl, but the employment of the store of energy in the latter to set in rapid rotation dynamoelectric machines for producing the electric current used in lighting.

At present sean-encines are chiefly used to drive the dynamo machines, but even with the hest engines and boilers it is well known that the fuel consumption is excessive compared with the actual work done. So good an authority as Sir William Armstrong has reccutly said that with a good condensing engine only one-tenth of the whole heat energy of the fuel is realised in useful work, and this is no exaggeration of facts. What therefore must be said of a small engine and boiler of the ordinary type? The main re:sson why the efficiency of even the best steam-engines is so low is because in an ordinary engine steam can only be used at a comparatively low temperature; for it can be proved that, with the temperatures which can be used in condensing-engines, the efficiency of even an imaginary perfect engine, without friction and loss of heat, cannot exceed $\frac{2}{100}$ or unly double the efficiency of a good modern steam-engine; that is to say that a good engine of large size uses only zo of the total heat, and that it is not possible to use more than ${ }^{2} \%$ with an engine of perfect mechanism.

It may be assumed that in large compound marine engines the fuel consumption is about $2 \mathrm{ll}$ s. per indicated horse-power, but it cannot yet l,e said that engines of this class and of very high power will be used in central stations for clectrical purposes; at any rate it must be remembered that besides other considerations there is a grent objection to the use of a single very large engine to electrically light a district, for the accidental stoplagre of this engine would plunge the whole neighbourbood into darkness.

Engines and boilers of the portable type are those generally used now for electrical purposes, and in a competition in England of several of the best engines of this class the fuel consump. tion was about $4 \mathrm{lb}$. per indicated horse-power per hour; but in daily practical work it may be assumed that 6 to $7 \mathrm{lb}$. more nearly represent their usual fuel consumption. This gives an efficiency of only about $\frac{1}{30}$.

With a hot-air engine there is this great disadvantage, that it is extremely difficult to prevent the lubricants from being burnt and the air vessel being injured by heat, since the latter vessel must be kept as hot or hotter than the air, becanse the tempcrature of the air is raised by an external fire. The only otber motor suital,le for electrical purposes (apart from machines driven by water or wind power) is the gas-engine. In the latter the power is obtained by the admission of an explosive mixture of gas and air into the cylinder, and the piston is driven by the explosion yroduced on the ignition of this mixture.

Now there is this great difference between a hot-air engine and a gas-engine, that in the latter the high temperature arising from the explosion is produced inside the cylinder, and not outside: so that, although the gas at the moment after explosion is extremely hot, the cylinder, jiston, and lubricant may be kept cool by an cxternal stream of water, which is of course impossible in a hot-air engine where the air is heated from the outside. Again, the very high temperature developed in the cylinder after the explosion has taken place is rapidly reduced by the piston doing work before there is time for the gas to give up much of its heat to the cylinder and piston. Stenm, however, can only be used at a very high temperature, provided the apparatus is made exceedingly strong.

With the present temperatures employed, the theoretical effciency of a gas engine might be raised from 56 to 75 per cent., if loss of heat by conduction, radiation, and convection, as well as friction, could be prevented; while in a condensing steamengine the greatest efficiency that could be obtained with the present temperatures employed could never exceed about 20 per cent.

It was thus shown that practically a gas-engine admits of being worked with much greater efficiency than either a steam-engine or a hot-air engine-that is to say, the percentage of heat the former turns into mechanical work is much greater than with the latter two. It was, however, necessary to consider the cconomy of working, which depends on the relative price of the fuel employed, and other iteias of working cost. Comparative esti. mates were therefore given of the working cost of a steam-cugine of the portable type and of an Otto gas-engine, both indicating 30 horse-power, for 300 days of nine huurs each (the borse-power about necessary to keep alight the 400 Swan incablescent lamps used to illuminate the Salle du Congries during this lecture). The cost of the coal-gas was taken at three shilings per 1000 cubic feet (or about $\mathrm{I} 3 \frac{1}{2}$ centime. per cubic metre, only about half the actual price in Paris), and it was thu; seen tha!, in spite of the very great relative efficiency of the gas-engine, the cost of working with ordinary coal-gas is greater than in the case of the steam-cngine. Ordinary coal-gas, however, has been prepared for pruducing not heat, but light, and bas therefore been elabo. rately purified at a considerable cost, so that when used in a gas-engine it is used for a purpose quite different from that for which it was intended.

A gas-engine burning illuminating gas is, in fact, in the same position as was a few years ago an electromotor, or machine for converting electric energy into mechanical power. An electromotor is an extremely efficient machine, but the fuel burnt to produce the electricity was, until quite recently, zinc, and consequently was far too expensive to allow the use of electromotors to be commercially successful. So in the same way, if it is attempted to work gas-engines by burning illuminating gas at even $13 \frac{1}{4}$ centimes the cubic metre, or half the actual price of the ordinary gas in Paris, they cannot even be worked as econo. mically as steam-engines, in spite of their superior efficiency and of the much smaller cost for superintendence. But if it be possible to manufacture for thcir use a cheap heating gas in the same way as it is now possible to produce electric energy econo. mically by burning coal, which is a much cheaper fuel than zinc, then the result, as you will see, becomes just the reverse, and small gas-engrines driven 1 ith such gas not only greatly surpass in cconomy steam.engines of the same size, but produce energy at a cheaper rate per horse:power than the largest steam-engines ever made.

The lecturer then described what had been done by Dr. Siemens and others who have made a heating gas for furnace work by means of passing air only, or air with a small admix ture of steam, through a mass of hurning fuel. Such gas, how ever, contains too much uitrogen ( 60 to 70 per cent.) to be suitable for gas-engines and other purposes requiring it to be used in small quantities, and the plant is large and costly. Reference was then made to what had been done by Mr. Dowson of London, who has perfected a gas-generating apparatus, into which he passes steam at pressure with a certain portion of air. 'This he effects by an arrangement similar to a steam-engine injector or a jet pump. The air thus drawn into the generator serves to keep the column of fuel through which it passes at a high temperature, without an exterior fire, so that the decomposition of the steam and the other chemical reactions take place without interruption. The working of the generator is thus regular, and the gas is produced without fluctuations in quality.

Experiments were made with a eudiometer, in which were three volumes of the Dowson gas and one of oxygen, and on exploding the mixture, 36 per cent. of the total disappeared. This corresponded with the following composition of the Dowson gas, viz. hydrogen, 20 per cent.; carbon monoxide, 30 per cent.; carbon dioxide, 3 per cent. ; and nitrogen, 47 per cent. by volume. It was also shown that this gas burns without smoke or any deposit of soot on a piece of porcelain, whether placed above or in the middle of the flame.

About 50 per cent. of this gas is combustible, and its calorific power, or the number of heat units produced by the combustion of a cubic metre, is $\mathbf{r}, 558,35^{8}$. Its calorific intensity is $2268^{\circ} \mathrm{C}$. To compare it with ordinary coal-gas we may take the calorific power of a cubic metre of the latter to be 5,590,399, and it. calorific intensity as $2554^{\circ} \mathrm{C}$.

In the Otto gas-engines a large proportion of air is mixed with the coal-gas, so that the effect of the explosion may continue during the stroke of the piston by the air taking up some of the heat produced; and as the Dowson gas requires less air for it: combustion, it is found that in the same cylinder there is not more nitrogen and unused oxygen in the charge of Dowson gas with its mixture of air, than with coal-gas and the quantity of air which is given to the latter. That is to say that the same power can be developed in the engine with coal-gas or Dowson gas if the supply of gas and air be exactly proportioned. 
The comparative explosive force of the two gas's calculated in the usual way is as $3.4: 1$, i.e. coal-yas has 3.4 times more energy than the Dowson gas. But because the combustion of carbon monoxide proceeds more slowly than that of carburetted hydrogen gases, and because the diluents present in the cylinder affect the weaker gas more than the coal.gas, in practice, with an Otto engine five volumes of the Dowson gas are used for one volume of coal-gas.

A table was given showing all the working expenses of an Otto gas-engine indicating 30 horse-power, and driven by the Dowson gas for 300 days of nine hours each, so that these expenses might be compared with those given for the steamengine and the gas-engine worked with coal-gas. These figures showed that a gas-engine worked with Dowson gas costs about $45 \frac{1}{2}$ per cent. less than when worked with coal-gas at 3 s. per Iooo cubic feet, and about $47 \frac{1}{2}$ per cent. less than a steam-engine of the portable type, after allowing in each case for repairs and depreciations, and interest on capital outlay. The most striking feature, however, was that with a steam-engine consuming $6 \mathrm{lbs}$. of coal per indicated horse-power per hour, and without adding any allowance for fuel used in getting up steam, and after work is done, 217 tons of coal are required to give the same power as 39 tons of coal converted into gas by the Dowson process. This represents a saving of about 88 per cent. in the weight of fuel.

Another practical consideration was that the quantity of the Dowson gas required to give the equivalent of rooo cubic feet of coal-gas was only 24 to 27 per cent. of the weight of the coal necessary for the latter. A further point of great interest is that a series of trials made with $3 \frac{1}{2}$ horse-power (nomimal) Otto engines driven by the Dowson gas, have proved that 1 horsepower (indicated) is obtained with a consumption of gas derived from $\mathrm{I} \cdot 46 \mathrm{lbs}$. of coal after allowing for the gas burnt in the manufacture of the gas as well as ro per cent. for impurities and waste of the coal. With gas-engines of larger power the loss due to friction is proportionally less, and the consumption of gas per indicated horse-power is less, thus with a 16 horse-power (nominal) engine which can indicate up to about 40 horse-power, the Dowson ga ; required would be about 90 cubic feet per indicated horse-power per hour, and this would give a consumption of coal of only $\mathbf{I} \cdot 2$ per indicated horse-power per hour.

Moreover, with a cheap heating gas not only can a saving in the motive power be effected for electric lighting, but this gas can also be used for domestic and industrial purposes, such as cooking and heating. It burns without smoke, so that when it is used in districts where there are many factories, or where much coal is consumed, not only will a great saving be effected, but in addition there will be freedom from a dark depressing atmosphere-the presence of which, the lecturer remarked, was the bane of London, and the absence of which formed the greatest charm of Paris.

NEW BIRDS FROM THE SOLOMON ISLANDS

$A^{T}$ a recent meeting of the Linnean Society of New South Wales Mr. E. P. Ramsay, F.L.S., \&c., Curator of the Australian Museum, read descriptions of the following six new birds from the Solomon Islands :-

Astur versicolor. - The whole plumage above and below is of a bluish slate-black, the base of the quills below ashy white, The length is about 17 inches, the wing $9^{\circ} 7$. The immature nd young birds are also described.

The adult male of Nasiterna finschii is described as having a crimson patch on the abdomen; otherwise like the female, which alone was previously known. The young of this species is also described; they differ in having a rosy tint on the cheeks.

A fine pigeon is described, and called Ianthenas philippane; it is allied to $I$. pallidiceps, but is not so dark in the plumage, being of a bluish slate colour, except the head and throat, which are white, with an opaline rose tint; the metallic reflections of the body are rose and light green; length 15 inches, wing $9 \frac{1}{2}$ inches. Two other pigeons of the genus Ptilopus have been dedicated to officers of Her Majesty's Navy.

Ptilopus richardsii.-A very beautiful and distinct species, having the head, neck, and all the under surface French gray, a very faint lavender crown, the wings and tail green; the former have a rosy carmine oblong or lanceolate spot on the scapulars; the latter has a terminal band of pale yellow. The nest, eggs, and young of this species are also described.

Ptilopus lewisii. - This bird was previously described in the same journal, and referred to Ptilopus viridis, and after. wards determined as the female of Ptilopus eugenia (Gould). A large series of both sexes and the young show it to be a new species. The general colour is green, the chest with a large patch of violet-purple. A description will be found in the Pro. ceedings of the Linnean Society of New South Wales, vol. iv. 1879, p. 73

Ptilopus johannis of Sclater is stated to be the male of $P$. solomonensis of Gray, and to $=P$. ceraseipectus of Tristram.

A fine new Chalcophaps has been named after its discoverer, Mr. Alex. Morton, Chalcophaps mortoni; it is like $C$. chrysochlora, but larger, and has no band on the shoulder; the young had been previously described under the name of $C$. chrysochlora, var. sandwichensis; the name is now altered to that of mortoni, and the adult described.

Myiagra cervinicauda, Tristram.-The male of this species is described, the type-specimen being a female; it belongs to the $M$. plumbea group of the genus.

Sternoides minor.-A smaller species than either of the previously known species, and differs in having a more curved bill, and all the secondaries, as well as the primaries, of an earthy-brown tint. Length about $7 \frac{1}{2}$ inches, wing 43 , tarsus $I$ inch:

A second paper by the same author contains a description of a new honey-eater of the genus Plectorhyncha, or of a new genus very closely allied to it. This species, which is of a uniform dull fulvous brown, has been named $P$. fulviventris. It comes from the south-east coast of New Guinea. Length about 8 inches, wing $3^{\cdot} \cdot$, tail $3 \cdot 2$, tarsus $\mathrm{I}$ inch.

$\mathrm{Mr}$. Ramsay stated that the trustees of the Australian Museum had recently received large collections from their collector in the Solomon Islands, and were daily expecting further consignments from New Guinea.

\section{SCIENTIFIC SERIALS}

Annalen der Physik und Chemie, No. 12, 1881.-On the interference of phenomena of thin plates with special reference to the theory of Newton's rings, by W. Fenssner.-On the dispersion of aragonite in an arbitrary direction, by V. v. Lang. -Remarks on Herr Lamansky's works on fluorescence, by $O$. Lubarsch.-Upper limits for the kinetic energy of moved electricity, by H. R. Hertz.-On disaggregation of electrodes by positive electricity and explanation of the Lichtenberg figures, by E. Reitlinger and Fr. Wächter.-Researches on the height of the atmosphere and the constitution of gaseous bodies (continued), by A. Ritter.-Contributions to the theory of electromagnetism, by W. Siemens, - Researches on the volume con stitution of liquid compounds, by $H$. Schröder.-On the theoretical determination of vapour pressure and the volumes of vapour and liquid, II., by R. Clausius. - On an equation which satisfies the kinetic energy of vibratory movements, by $\mathrm{S}$. Oppenheim.

Fournal de Physique, December, I881.-Hydroelectric and hydromagnetic phenomena, by C. A. Bjerknes.-Variation of indices or refraction of gypsum with temperature, by H. Dufet. -On the measurement of temperatures by means of the mercury thermoneter, by M. Pernet.-On the singular polarisation of electrodes, by A. Solokoff.-Discourse of M. Dumas at the International Congress of Electricians.

Rivista Scientifico-Industriale, December I5, 1881.-Displacements and deformations of the spark in air by electrostatic action, by R. Righi.--On some curious conformation of the spark in air, by the same.-Endogenous origin of the rosts of plants, by S. Hriosi.

The last two parts of the Memoirs (Trudy) of the St. Petersburg Society of Naturalists contain, besides the minutes of proceedings, the following interesting papers (vol. xi. fascicule 2) :-A preliminary report on the structure of corals, and on the origin and development of the egg of the Medusa leucope before fructification, by K. S. Mereshkovsky. - Materials for the flora of the Onega region, by A. K. Hiinter; and of the neighbourhood of Povenets, in the government of Olonetz, by Chr. Gobi.-(Vol. xii. fascicule I) :-A geological description of the neighbourhoods of Krasnoye and Tsarskoye Selo, by R. Kudryavtseff and J. Lebedeff (with map and plates). - On the aërial roots of the Acanthoriza aculeata, by K. Friedrich (with plates). - On the influence of light on mushrooms, by K. Regel.-On the Imatra waterfall and Imatra stones, by P. Venukoff.-Report on the expedition to the White Sea, by L. Tsenkovsky. This volume 